\title{
"Your Eyes Open and So Do Your Ears": Centering Knowledge of Families With Refugee Backgrounds During a Follow-up Interview
}

Journal of Family Diversity in

Education, 2021

Vol. 4, No. 1, pp. 1-19

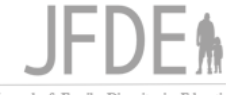

\section{Cynthia C. Reyes, Shana J. Haines, Hemant Ghising, Ashraf Alamatouri, Madina Haji, \& Rachel Hurwitz \\ University of Vermont}

\begin{abstract}
In an exploratory case study of partnerships between educators and refugee families recently resettled in the U.S, we conducted follow-up interviews with each of the ten participating families during year one. In this paper, we report on themes from these interviews highlighted in three family case studies. We used methodological approaches that enabled us to reenvision and interrogate the power structure inherent in research relationships between 'researcher' and 'researched." The purposes of the additional interview were to conduct a member check on the data we had gathered, understand what had changed since our initial interview with the family, and gather families' feedback about our comportment and methods. The two-part question was, How might decolonizing methods from a postcolonial lens serve as guideposts for disrupting research methods with families with refugee backgrounds?, and How did partnering with transnational student researchers inform ways of representing the family narratives? The follow-up narratives suggest a complex understanding of building knowledge within the limitations of a conventional research paradigm.
\end{abstract}

Keywords: refugee families, community knowledge, decolonizing, postcolonial

\section{Introduction}

There has been a great deal of writing on the dilemmas of translating practices that follow a biomedical model for qualitative social science research, particularly with refugee-background populations (Block et al., 2013; DeHaene et al., 2010; Dyregrov et al., 2000; Ellis et al., 2007; Jacobsen \& Landau, 2003; Nakkash et al., 2009; Perry, 2011; Schrag, 2010). Examining research methods with families and children who have endured transnational migration, as well as the ethical complications of representing their experiences, is a key issue we explore in this piece. As a research team comprised of U.S.-born education professors and students, and students from the global majority (i.e., South Asia, Middle East, Africa), we organically explored decolonizing methods for determining how to partner with each other in a study called Centering Connections: Examining Relationships Between Refugee

Corresponding Author:

Cynthia Reyes, Associate Professor, University of Vermont, Waterman Building Room 410, Burlington, VT, 05405, USA

Email: Cynthia.Reyes@uvm.edu 
Families and Educators (Reyes et al., 2021). Centering Connections was an exploratory study of 10 families with refugee backgrounds across five different language communities who connected with their children's teachers in U.S. public schools. This subject is part of a larger longitudinal study that examines the intersection of decolonizing research methods and postcolonial theory in a project with families with refugee experiences.

We first examine how we use the term decolonizing methods and what it means to decolonize. The term is complex and rooted in unique foundational and historical enterprises. Scholars who engage in decolonizing Indigenous methods (Chilisa, 2020; Smith, 2012; Smith et al., 2019) seek to decenter colonial epistemology in order to "struggle and assert their claim for humanity" (Smith, 2012, p. 27). Other scholars describe decoloniality as "ways of thinking, knowing, being, and doing that began with, but also precede, the colonial enterprise" (Mignolo \& Walsh, 2018, p. 17). According to Mignolo and Walsh, decolonization is not an academic field, but a dynamic and fluid process that depends on a variety of local histories, politics, and ways of communing. As emerging learners of decolonizing methods and postcolonial theory, we gain inspiration from these differing bodies of knowledge and humbly describe decolonizing as an ongoing praxis for critical deconstruction of Western research methods in the field of education. In her book examining educational research as a site of coloniality, Patel (2016) notes the damaging ways in which researchers from dominant cultural backgrounds have influenced research practices such as gaining informed consent, conducting interviews, and representing nondominant cultural groups. Many critical scholars describe the responsibility of researchers to interrogate their "ontological entry-points and impacts" (Patel, 2016; p. 57) in their research by considering self-examining questions such as "Why me?," "Why this?," and "Who now?" (Mignolo \& Walsh, 2018; Smith, 2012; Smith et al., 2019). Patel also recognizes the limitations of deconstruction to transform conditions structurally and materially. Nevertheless, these prompts resonate with the relational tensions that emerged in our study between Western and non-Western approaches to research.

Desiring to center participants' situated lives during our analysis, we used methodological approaches that enabled us to reenvision and interrogate the power structure inherent in research relationships between 'researcher' and 'researched'. Partnering with students from the global majority also influenced our understandings of power and knowledge construction when considering prior transnational ways of knowing. Therefore, our two-part question was, How might decolonizing methods from a postcolonial lens serve as guideposts for disrupting research methods with families with refugee backgrounds, and how did partnering with transnational student researchers inform ways of representing the family narratives? In this piece, we examine what we learned through our research methods by conducting two interviews with 10 refugee families, using a total of five different languages (Nepali Bhutanese, Somali, Mai Mai, Swahili, and Arabic). We used follow-up interviews as a way to assess our conduct with the families and to provide them with the opportunity to share with us what they learned from the first interview.

Second, we critically explore the use of a postcolonial framework for considering relationships with refugee families who are newly resettled. We examine the tensions of engaging in research in refugee communities and discuss attempts at bridging these tensions by clarifying what they are through our reflections of the follow-up interviews with families. Many researchers who conduct research in refugee communities refer to a dual imperative: producing knowledge that meets the criteria of the academy and protecting the refugee community at the same time (Block et al., 2013; Jacobsen \& Landau, 2003; Nakkash, et al., 2009; Schrag, 2010). The problem with the dual imperative is that one misses the opportunity to develop intentional relationships with families if they focus solely on operationalizing the research methods. The desire to protect the refugee is an obvious ethical commitment of the researcher, but the manner in which this commitment may be fulfilled can have deleterious consequences for refugees. Third, we describe the methods we used to hone a critical 
reflexivity that considers decolonizing our ways of knowing and doing research. Afterwards, we provide narrative descriptions of the families while also situating ourselves in these narratives to be more transparent about who we were and what we did during the interviews. Lastly, we discuss how decolonizing methods and a postcolonial framework compelled us to examine tensions of power dynamics and knowledge construction in the study.

The research team consisted of two U.S.-born co-primary investigators, one Filipina American education professor and one White education professor, and four university students, three of whom were personally invested because they also served as liaisons interpreting between the university and the communities that participated in our study. The two graduate students were from Bhutan and Syria and were also planning their graduate work around this study, while the two undergraduate students were from Somalia and the US. Together, these students from the research team (hereinafter referred to as student researchers) served as intermediaries to help arrange interviews with the families and act as interpreters. Their roles extended to shaping how we (the research team) would naturally construct norms for relationship building. It is important to note that we self-identify here, because throughout the study we shared with each other our identities and prior ways of knowing, which we discuss in our reflections on research methods below. Our self-location stories (Windchief \& San Pedro, 2019) acknowledged the different filters we used to understand participant stories, and sometimes roles were reversed when the professors depended on students to help them interpret participants' values, gestures, or experiences.

\section{Unpacking “Alterity": The Complexity of Refugee Lives from a Postcolonial Lens}

Postcolonial theory can provide a critical framework for analyzing and centering the historical, social, political, economic, and aesthetic elements of the subaltern or the Other. Postcolonial scholars have been committed to critiquing the material consequences and the dangers of ethnocentrism rooted in Western/Enlightenment thinking. They draw attention to an understanding of alterity or difference, a hostility to the Other, and the dangers of dominant knowledge (Bhabha, 1994; Fanon, 1963; Said, 1993; Spivak, 1988). Postcolonial theory is also instructive for questioning the production of Western knowledge and representation of voice.

In research and popular literature involving families and children with refugee experiences, there is an all-too-common paradigm that constructs their experiences as displaced victims from civil war or governmental upheaval whose lives are perpetually fraught with peril and trauma throughout their migration journey (Haddad, 2008; Hemon, 2018; Nguyen, 2018). But how does one describe humanity in the stories of refugee families and children without pathologizing their experiences? According to Hemon (2018), literature is key: "The very proposition of storytelling is that each life is a multitude of details, an irreplaceable combination of experiences, which can be contained in their totality only in narration" (p. 93).

Many scholars agree there are ethical ways to develop research that is humanizing and that protects families from exploitative means (DeHaene et al., 2010; Isik-Ercan, 2010; Jacobsen \& Landau, 2003; Mackenzie et al., 2007; Perry, 2011; Pittaway et al., 2010). However, the question remains of who represents these stories and how. Postcolonial scholar Gayatri Spivak has described the contributions that Marxist theory made to the poststructural movement but has also interrogated its limitations, especially around the notion of difference. She challenged the academic elite with her question about who could really speak for the "subaltern," individuals who could not speak for themselves because of their perceived inferiority in society (Gandhi, 2019; Spivak, 1988). We are curious about the concept of alterity, the state of being or making oneself different from another, and 
how alterity operates in a postcolonial world. Fanon described the difference between the colonizer and the colonized subject who is "[c]onfronted with a world configured by the colonizer, [and] ... is always presumed guilty" (1963, p. 16). However, Fanon goes on to say that although the colonized may be made to feel inferior, they are by no means convinced of that inferiority. Gandhi (2019) states it is this complex relationship that so vexes postcolonial scholars because there exists no comfortable alliance between the colonizer and colonized in a postcolonial world without the risk of further marginalizing the Other.

According to Andreotti (2011), Spivak is suspicious of any attempt on the part of Western scholars to speak for the subaltern or even for any "pure form of subaltern consciousness" because such efforts to produce such an unadulterated voice relies more on the scholar's goodwill or benevolence, which sooner or later ends up silencing the subaltern again. The debate for where this conclusion lies is beyond the scope of this paper; however, the ideas that emerge from these debates are useful for interrogating the scholar's goodwill. From our emerging understandings of postcolonial theory, we highlight these difficult discussions about the subaltern and the concept of alterity because they are useful for us as educational researchers to explore our own constructions and viewpoints of knowledge and power. Forced to examine the ontological roots of these concepts, we come to realize that research methods, if left unexamined, risk generating observations of differences in individuals or groups that result from a reduced, objective, and relativistic manner.

The historical and political lives of families with refugee experiences are constitutive of power and powerlessness as they seek to negotiate the terms of the conditions of their lives, which have mostly been controlled by geopolitical laws and governmental whims. Bringing attention to these conditions without perpetuating the paradigm of difference requires reflection when seeking to highlight the humanity in refugee families' experiences. As we reflect on participants' stories of resettlement, we evoke Said's writing on imperialism and how domination of land and the inequities associated with it are "perceived facts of human society" (Said, 1993, p. 19). Many of the families in our study who fled from Iraq, Congo, Bhutan, Syria, Kenya, or Mozambique shared common stories: living a content life before the violence found them, escaping from violence in their country (and sometimes in the countries where they initially sought refuge), enduring hazardous travel, and encountering postmigration trauma in perplexing new institutions and policies. However, upon closer analysis, these experiences varied from family to family. Words they extolled time and again throughout the study were "home" and "community." Being both emotionally and geographically informed, we reflect on our own decolonization to develop an operating praxis when working with families in these liminal spaces in a research context. When we draw upon postcolonial theory, we can also problematize static notions of non-Western cultures and languages as well as ask the question of "Whose gaze?" when recording the families' experiences or when listening to their stories through the equally subjective interpretations of the student researchers. In her work that analyzes educational policy discourse, Andreotti (2011, p. 107) proposes an actionable postcolonial lens that seeks to resist "uncritical celebration of fixed identities and ethnicities in the discourse" related to multicultural education. Decolonizing our methods is an intentional way for the research team to work out what criticality means, and postcolonial theory provides a body of knowledge that troubles the notion of alterity in dynamic and relational research settings.

\section{Study Overview}

\section{Our Methods: Working with Communities}

In conducting Centering Connections, we sought to obtain a deeper understanding of what connections flourished between families and schools and why. Using an embedded case study design 
(Yin, 2009), we qualitatively explored family-school partnerships through interviews, observations, and document collection. We first sought consent to conduct this study from two school systems. Then, through purposive sampling (Maxwell, 2012), we worked with community members to identify families who came to the US as refugees within the preceding 36 months and lived in two refugee resettlement communities in the Northeast.

Participants included 10 families (four Bhutanese Nepali-speakers, one Somali, one Somali Bantu, one Congolese, and three Iraqi), 17 teachers (at least one English Learner [EL] and one general education teacher for each student), six home-school liaisons employed through the school district, and two administrators. All students were between 10 and 17 years old.

In our first interaction with the families, we explained the study and asked for consent, which involved one or both of the co-PIs and a student researcher visiting their homes. The student researcher explained the study to them and inquired if they would be interested in participating. For each family in this study, we conducted an interview of the whole family, an interview with the children, one interview with at least two of the children's teachers, one with their school-based homeschool liaisons, and one with an administrator. The families and children identified which teachers they wanted us to invite for an interview. We then returned to the family for a second interview. The interviews with the families and children were mostly conducted in their native language by the student researchers, and the interviews with teachers, liaisons, and administrators were conducted in English. We conducted a total of 55 interviews, and interviews with families lasted anywhere between 45 minutes and 3.5 hours.

Throughout the study, especially between the first and second interviews, we strove to integrate self-reflection activities that seemed organic to the process and that progressively became more intensive as we broached personal topics related to childrearing, family dynamics, education, teaching, and cultural rituals. We began to "think more narratively" (Clandinin \& Connelly, 2000), examining the ontological intersections between the families' stories and our own as family members, students, teachers, children of immigrant and refugee families, or travelers and workers in other countries. "Just as reductionism makes the whole into something lesser, sociological and political analysis can also make the whole lesser through the use of abstract and formalism" (Clandinin \& Connelly, 2000, p. 38). To counter what we perceived was a formal and abstract process, we sought to "slow down" these reflection activities and aspired to create something more dynamic and whole: knowing each other and inviting the dismantling of hierarchical mechanisms within the research study. The co-PIs were aware of their position of power opposite their students, but as the study continued, they made it clear to the student researchers that their knowledge and skills were invaluable to the process. Although at the time we did not use the term "decolonize" to describe the reflection process we were engaging in, we were approaching responses to the following questions: Who were we to the families? What might the families think of the activities we were doing? How do notions of status and power influence relationships between the professors and the student researchers, between the student researchers and members of their own communities, and between the professors and the families? We recorded these reflections during the team's bimonthly meetings and during two research retreats. During the first research retreat, we each wrote identity narratives related to what we learned about ourselves during the study and what we hoped to learn as we delved deeper into our work. The narratives fostered a fundamental trust among the team as professors learned about their student researchers' aspirations and the student researchers learned about their professors' family lives. The narratives also informed our understandings of family experiences. Nevertheless, it is this trust that instilled in the team a collaborative approach for communicating the study to the families and gaining their consent. 


\section{Getting to Know the Families: Three Case Study Narratives}

To illustrate the substance of the second interview, we introduce three of the 10 families who participated in Centering Connections. We chose these three family case studies because their narratives highlighted themes that emerged across participants. The data referred to the ways that decolonizing methods enabled reciprocity and forms of trust, but they also showed limitations in the way such methods are practiced within a conventional research study. These methodologies enabled tensions to emerge when considering the assumptions that some families and teachers had of the other. These narratives also reflect the research interviews that we used as field texts (Clandinin \& Connelly, 2000), and through the generative perspectives of the student researchers, we developed them into narratives of our interactions with the families.

\section{Gogo}

Gogo and her five children (aged 3-13 years old) were Somali Bantu. Gogo's daughter, Habi, a 13-year-old who was attending a newcomer program for newly arrived students, participated in the study. The family was resettled from Kenya, where they had been living in the Kakuma refugee camp among a mostly Somali Bantu population for 20 years, and they had been living in a northeastern city for only two weeks when we met her for the first interview. As a single mother of five children, Gogo had extended family in the area where she resettled and moved into an apartment with her uncle's family. Although Gogo spoke with a quiet voice, her mannerisms with the student researcher seemed friendly and relaxed. After the interview, Madina admitted to Cynthia that, in Gogo's culture, Gogo was considered her grandmother because Gogo was her grandmother's sister. Gogo's young children were therefore considered to be Madina's aunts and uncles. Madina, who had lived in the US for 16 years, visited Gogo's home regularly to help her with shopping, childcare, and cooking.

During the first interview, Gogo expressed determination to find a job. When Madina asked Gogo if she found a job, she used the Mai Mai word for "given" rather than "found," which prompted Gogo to ask, "Who's giving me a job? I'm looking for it! I only go to school. I want the job!" She wanted her own place to live but needed a job first. She said that in the refugee camp where they lived, she would leave the children while she used her "driver card" (a document allowing her to leave the camp or "go on the road") to go to Mombasa or Nairobi for days at a time to work and then send money back home to her family. She said, "In Kakuma, they only serve maize ... and you can't live on that. We all can't be sitting around waiting for that. So, you get up and go out ... leave the camp." She heard that a parent could be arrested for leaving their children at home alone in the US, however, so she was concerned about how she would be able to find a job that would allow her to come home in time to collect her children from school.

She had neither met her children's teachers nor received any correspondence from the school, according to Gogo. Teacher interviews confirmed that they had not met Gogo, and they recognized that it might be difficult for her to meet with the teachers of all four of her school-aged children. Gogo was not particularly concerned about her children's schools because, as she noted, any school was better than the school her children attended in Kakuma, where a single classroom would hold 150 students. She said, "They teach English, but only the ones that actually are determined to learn, learn something. The school walls have holes in them. What are kids going to learn in such a big classroom with just one teacher?"

\section{Leenata, Guaresh, and Suchandra}

On the day that the research team consisting of Shana and Hemant met with Leenata and Guaresh, their extended family was visiting from Canada to celebrate Dashain (celebration of Durga). 
Five adults sat packed together on the couch and insisted the team members sit in the bigger armchairs. Leenata's husband, Guaresh, set up a folding chair across from us. The teens, children, and one other adult woman (Leenata's deaf sister-in-law) sat on the floor. Hemant had arranged to meet with Leenata, but Guaresh told us that she was in the garden and would be home soon. It felt a bit awkward to arrive in the midst of a festival celebration, with participants in elaborate clothes and decorated faces, and ask personal questions about refugee resettlement with so many people in the room listening. We started the interview with Guaresh, and we learned that the family had been farmers in Bhutan before migrating to Nepal and living in a refugee camp there for 22 years. In the refugee camp, the large extended family that had lived together in Bhutan was divided across numerous smaller dwellings. One of the smaller family units then migrated to the US, leaving behind the extended family they had lived with in Bhutan.

The parents had no formal education, but the children had attended school at the United Nations High Commissioner for Refugees camp in Nepal. Guaresh stated, "In Bhutan, I was a farmer and worked in agriculture. In Nepal, I worked for my children's education. I made other people's houses better, but mine was still a shack." Neither the mother nor the father was literate, though Guaresh said, "I learned to write a little-my name_-but I can't speak in English." Guaresh said he did not know much about the children's school because he worked during the day and the school had Leenata's phone number, not his. When Leenata came home from the garden, she was trailed by her two eldest daughters, and they each carried a large parcel full of the early October harvest. Leenata said that Suchandra, her 13-year-old daughter who was participating in the study, was doing fine in school, because she had never heard otherwise. The parents had never met her teacher even though Suchandra had been in the same "newcomer" class for three years. The parents stated that they "had never been invited to the school." We conducted an interview with Suchandra immediately following the interview with her parents. All family members moved to the kitchen to prepare food for the festivities, and Suchandra moved to the couch. She spoke in a whisper and did not make eye contact. Shana and Hemant conducted the interview and felt pained because of her shyness, but we had to ask many of the questions numerous times in order to hear her answers.

\section{Sabiya and Ahmed}

Sabiya and Ahmed were from Iraq and were the parents of six children (one daughter in community college, two daughters in high school, one son in elementary school, and a younger boy and girl at home). When Cynthia, Shana, and Ashraf met the parents for the first interview, the couple was eager to share what they and their children experienced during the first few months at their new school. Their second older daughter in high school, Sahar, who was 16 years old, was supposed to be the focal child for the study, but Sabiya and Ahmed also wanted to include Sahar's little brother Mahdi, who was 10.

When her children attended US schools for the first time, Sabiya was disappointed by the lack of awareness the teachers had of her children's skills. She did not understand why they evaluated her children's intellects and knowledge based solely on their linguistic skills. As Ahmed described it, not knowing the English language was the primary problem. He felt that the teachers did not initially have high expectations of his children. He said, "My kids have studied physics, chemistry, and some English. But when they came here, they put them in classes that teach $1+1=2$." Sabiya's voice became more and more passionate as she described her children's frustrations with being placed in the lowest level classes offered at their schools. She said,

Yes, of course ... My girls cried all the time. It means your body-your head is some problem you have a problem. You are not normal. You know what I mean? For six months, I believe we suffered that, and then I went to the teacher. I told her we have a background. We have studied we studied hard, but the problem is that we do not know how to speak English. We know Arabic. 
We know science, math, everything, but the problem is just that. If you fix this problem, you will see that my girls are so clever.

This idea of "fixing the problem" became a theme throughout the interview as Sabiya described how she perceived US schools and teachers.

These snapshots provide an overview of our first meetings with the three families, and although brief, they are necessary to explain the value of the follow-up interviews several months later. In the following sections, we discuss how the second interview demonstrated to participants that we valued family knowledge and the information they shared with us; this step provided us with a different idea of how one's comportment in a research setting could be interpreted and examined.

\section{The Second Interview}

To decolonize our methods, we problematized the idea of extracting knowledge from refugeebackground participants during the interview (Chilisa, 2020; DeHaene et al., 2010; Dyregrov et al., 2000; Mackenzie et al., 2007; Pittaway et al., 2010). Based on a case study that specifically examined refugee families' experiences of the interview process (Dyregrov et al., 2000), we developed a modified protocol for follow-up interviews (see Figure 1). We asked family members their feelings about the first interview, focusing on the following topics, which we modified from Dryregrov et al.'s study (2000): clarification, personal learning, gaining access, the interview, and the period following the interview. The co-PIs generated these areas of focus based on what we learned from Dryregrov and colleagues' article about developing follow-up prompts that may gather more personal input from the families. Since we developed these questions for the IRB protocol, we did not have time to review them with the student researchers until after they were already approved by the human subjects review. In hindsight, these words already possessed a formal and distant ring to them due to their semantic nature. While we intended to center the experiences of families, we still depended on a semi-structured protocol in the service of examining our own methods.

\section{Figure 1}

Modified Protocol for Follow-Up Interview
Focus
Prompt
Clarification
Does this summary capture what you shared with us? Are there any parts of this summary that are inaccurate? Where should we clarify the data?
Personal Learning What has changed since our last interview? Do you have any new observations? Have you learned anything new? What caused these changes?
Gaining Access How did you feel about bow we contacted you to participate in this research?
Interview How did you feel about the interview itself? Did you enjoy any aspects of the interview?
Compensation for We wanted to give you something for your time, so we gave you a gift card. Is there anything Time we could have done to compensate you better for your time? 
We designed the second interview with three main purposes in mind, and all of them were aimed at developing a more open relationship with participants than if we had conducted one isolated interview. We hoped to examine the role of reciprocity in our relationships with the families by doing the following: conducting a member check in which we summarized what we learned during the first interviews with all of the participants, providing families with the opportunity to revise our inquiries and discuss any ways their participation in our study affected them, and, lastly, inviting families to provide feedback about our comportment from the first interview.

\section{Examining the Second Interview Through Decolonizing Moves}

When we met with the families a second time, we brought new information that we had learned from the interviews with the teachers and the home-school liaisons. Immediately, we could see that the families had thought a great deal about our previous conversations regarding their role in their children's education and their relationships with their children's teachers. In the following narratives, we describe the shift in perspective that families had about their children's education as well as the tensions that emerged relating to our positionalities as researchers and teachers. In addition, we discuss how the question to the families about our comportment during the first interview may have been presumptuous and unnecessary.

\section{Gogo}

We visited Gogo at a new location — a large apartment she was able to find through her network of community friends. Cynthia led this interview, but Madina interpreted, and Shana also came. We found Gogo at home preparing sambusas, dough filled with beef and spices and then fried in a small galley kitchen. The student researcher took off her coat and washed her hands at the sink. Cynthia and Shana followed what their student was doing. Gogo carried the large bowl of filling, her fingers smeared with sticky dough, from the small kitchen into the living room where we could all sit together without halting the sambusa preparation. Following Gogo, we all sat down on the carpet, forming a small circle around the bowl. Madina casually put her hand in, pulled apart some of the sticky dough, and began to shape it with her hands into a little ball, eventually flattening it into the shape of a small half-moon. After a little hesitation, we each grabbed some dough with our fingers. It felt natural to imitate Gogo and Madina's actions, and we proceeded to do the same thing (though the results were not nearly as beautiful). Sitting on the floor shaping and patting the sambusa dough, occasionally looking up for approval from Gogo that we were doing it correctly, we conducted our interview. All five children were also in the room, watching TV.

Even though we were researchers there for a study, our identities as mothers who had experienced making dinner while caring for children informed the way we conducted the conventional interview process. We all sat in a circle around the bowl of dough with flour on our hands and teased a younger child who was sneaking behind us to try and snatch Cynthia's mobile phone as we conversed about how Gogo's children were doing in school. The act of sitting on the floor and offering to help make sambusas created a moment that was relaxed rather than formalized, allowing for routines to continue. We joined Gogo in her activity, which also positioned her as the expert. 


\section{Journal of Family Diversity in Education}

There was a lot that had transpired since we last saw Gogo. She had found a job at a nursing home working directly with the elderly two days a week, and she was learning some English from the new position. She talked about how much she enjoyed the work and how it reminded her of providing massage therapy to children with physical disabilities in Kenya. She was using a similar approach with some of the elderly, and being able to transfer her knowledge to the new setting seemed to bring her satisfaction. Although she had experienced a setback in her own educational goals to pursue becoming a nurse, Gogo communicated a familiar hopefulness we had observed in the first interview. She seemed less worried since the last time we had met.

Throughout the interview, Gogo sounded less mystified about the expectations the school had of parents. Gogo shared that our first interview prompted her to meet with her children's teachers. She explained, "Yeah I met with the teachers. I went to the schools; they said their learning is good. They were moving on to the next grade levels." She had finally met Habi's teacher, Ms. L. She was still confused by some of the correspondences from school, however. For example, she did not understand how to read the report card and could only make sense of it with the help of other family members like Madina. She did not know how to use email to correspond with teachers. She also shared that, more recently, her older son's teachers had been calling her to complain about her son getting into trouble. She said that all she could do was say that she was sorry for his behavior. As we talked, a couple of the children interjected to answer for their mother in a joking manner. When Madina asked what activities the children were doing after school, Gogo said she took them outside to play, to which Habi immediately denied, "No you don't!" Madina laughed and told Habi to behave.

Toward the end of the interview, we asked Gogo what she had learned about the interview process specifically. She said,

It's good. If a person is sitting at home and someone comes to them and tells them things, that's a good thing. Your eyes open up and so do your ears. If you were sleeping, you would wake up; you understand everything. The children-you see their situation. It's like this.

From a postcolonial perspective, Gogo's insights and actions took on a different set of values and meanings than seemed possible through the IRB definition of her as a "vulnerable participant." Gogo's knowledge of the norms and practices of US schools was growing. However, as former classroom teachers, we were aware of implicit biases that schools had of nondominant families feeding into the perception of families that knew little and had to be taken care of, further perpetuating the "vulnerable" stereotype of refugee families (Ishimaru et al., 2019). These biases were often rooted in normative understandings of how to be successful in schools and how to decode school language in order for the children of mainstream society to navigate school successfully. Such knowledge rarely accommodates other forms of understanding that is not codified in the English language. We came to learn about Gogo's fierce determination to make a new life for her children without full knowledge of English or the underlying cultural knowledge one learns from being born and raised in the US (which gives one the ability to decode codified norms and practices). As such, our eyes and ears opened to the predictable assumptions and expectations that researchers may have of individuals like Gogo who are classified in a particular way in an IRB protocol.

Months prior, Gogo's reality consisted of leaving the refugee camp to find work and forage for extra food. As a single parent of five children whose husband stayed behind in the refugee camp with his second wife and their children, Gogo had accomplished a great deal in just a short period of time, and she spoke of dreams she had for herself and for her children. During our interview with Ms. L, it became increasingly clear that she and Gogo's children's other teachers did not know Gogo that well. In fact, Ms. L mentioned that she never got to know the students' parents unless they were waiting outside her door after school to pick up their children. Educational research on refugee families has found that there exists a perception that non-English speaking families are unable to support their children's schooling because of their lack of English proficiency. This unfortunately leads to the family 
being blamed (Dryden-Peterson, 2015; Haines et al., 2015; Haines et al., 2018; McBrien, 2005; Olivos et al., 2010). We contemplate the original purpose of the study, which is to better understand the partnership between families with refugee experiences and schools, and we see a fundamental unfairness in the way that the partnership could be misconstrued to seem more beneficial for the family than for the school.

\section{Leenata, Guaresh, and Suchandra}

Before Cynthia, Shana, and Hemant met with Suchandra's family for the second interview, we had just learned that Suchandra, according to her EL teacher, was making progress in eighth grade but was reading at the first-grade level. Furthermore, the teacher stated that Suchandra was quiet, shy, and reserved at school, which we confirmed through our own observations at school as well as during the first interview with her. According to her EL teacher, "she doesn't get particularly driven about anything. She doesn't get particularly stressed about anything. She's the most pleasant person. And I've noticed that ... she doesn't have that real — that hungry attitude about learning. She's very passive about it." Her teacher told us that she only met with families when the children had difficult behavior; since Suchandra was well-behaved in school, she had never reached out to the family to schedule a meeting.

Upon returning to Suchandra's home for the follow-up interview, we were filled with ambivalence as we reflected on the solicitous description that Suchandra's teacher had of her as a student. The characterization of a young adolescent refugee girl as passive and quiet represented an implicit bias held toward children who do not reflect the normative school behaviors ("she doesn't have that realthat hungry attitude about learning") because of perceived cultural and linguistic differences (Bermudez et al., 2016; Guierrez \& Rogoff, 2003). We felt that even coming from a well-intentioned practitioner, this description of Suchandra could perpetuate a deficit perspective that is well documented in the educational literature on emergent bilingual and multilingual learners (García \& Kleifgen, 2018). This perspective also demonstrates a lack of understanding that it generally takes seven to 10 years for English learners to acquire academic English and that a more, rather than less, challenging curriculum is beneficial. The teacher expressed that Suchandra was doing well because she was not disruptive in class, but she did not get to know her or her family.

In a tricky balance of researching the phenomenon of what was taking place, we found ourselves in an ethically complex position of intentionally influencing the very actions we were researching. Should we share information that might influence the relationships we sought to understand? We decided to describe what the teacher had told us about the reading curriculum and the online program that Suchandra had access to through her school-issued iPad. We asked her parents if they had ever received any information about her reading levels. By highlighting this question, we heightened the parents' awareness of their daughter's reading ability and introduced the idea that they could help her practice her reading even if they were not readers themselves. Upon receiving the information and responding to our questions, Leenata expressed concern about how her daughter might do in high school. Leenata also voiced her apprehension about the level of rigor of Suchandra's schooling, to which Cynthia suggested, "I hope ... when you meet with Suchandra's teachers . . you bring up the questions that you had asked earlier [about] wanting Suchandra to learn harder materials. I think they're very good questions to ask." Leenata responded, "Usually in the evenings it's hard for me to do it, but I will plan to talk to the teachers about making Suchandra learn more English."

We motivated Suchandra's parents to advocate for their daughter. We had also asked questions to her EL teacher, aiming to discern her perception of whether Suchandra's parents understood that she was not reading at grade level. These questions prompted the teacher to reflect on the general difficulty of explaining reading levels to parents, but it also caused her to think about the impact of not sharing this information. 


\section{Journal of Family Diversity in Education}

Furthermore, in the second interview, the discussion about goals and dreams for their daughter had prompted Leenata to reflect on her desire for her child to be challenged more by the school so that she would be ready for college. In the second interview, Leenata stated,

We wish that our kids would be challenged with hard subjects. We actually don't know what's happening in the schools. But as [parents], we feel that they should have some hard courses so that they learn from it. More subjects will help them to learn more about the laws of this country, so that helps when they grow old and become an adult. Suchandra feels that English is hard, and she could work more on that. She could stay after school and learn more and better English.

This sense of agency and desire to improve the education her daughter was receiving was a significant shift from the passive acceptance of the school's practices that Leenata and Guaresh had expressed in the first interview. The questions we had asked in the first interview had evoked a change in the way they saw their role constructions in regard to Suchandra's learning. This shift illustrated Carter and colleagues' (2008) description about the effect of participating in research: "The act of participation had an epistemic dimension-it reconstructed one's knowledge about one's own experience-and an ontological dimension-it reconstructed the self' (p. 1271). After this second interview, this family continued to shift from maintaining a passive role in their daughter's education to taking a more involved position by requesting a parent-teacher conference with the teacher they had never met and by helping Suchandra access a supplemental literacy program on her school iPad.

There was also a stark contrast in Suchandra's behavior from the first interview to the second. During our second interview with Suchandra, we were amazed when she greeted us openly, spoke to us in a clear voice, and made eye contact with us. It was almost hard to imagine how quiet and shy she had been during the first interview. Modifying the semi-structured protocol, we asked why she was speaking more openly. She replied, "Yeah, like, I realized I needed to talk more. After you left last time, my parents asked why I spoke so quietly. They said, you need to speak up. I decided to speak up more, even at school." When we turned to Leenata to ask what she thought about this, she said, "It's not that we asked her to prepare to talk more, but we have been encouraging her: 'you know things, and you should be able to speak." Her mother's encouragement had greatly affected Suchandra's use of her voice, compelling us to imagine the effects a stronger partnership with her children's teachers could have.

\section{Sabiya and Ahmed}

When Cynthia, Shana, and Ashraf returned for the second interview, we asked Sabiya how things were going, especially for her younger son Mahdi, then 11 years old, who had been struggling in fifth grade. Sabiya and her husband seemed less critical about their expectations of teachers. Time had passed, all of their children seemed to be settling into their schools, and the parents seemed to have found an effective method of advocating for their children and partnering with their children's teachers. Sabiya and Ahmed, after voicing frustrations with their children's teachers to us and envisioning their ideal relationship with the teachers during the first interview, persevered to form a trusting partnership with their son's teacher. Over time, their oldest daughter went on to register for community college so that she could receive more challenging instruction, while the second oldest daughter found teachers who advocated for her and was able to take more challenging classes.

Sitting in their living room, sharing Turkish coffee, and listening to the families' stories of the countless ways they supported their children in their education and the ways they negotiated schooling in Syria was critical for us to learn and reaffirm our knowledge about the families. According to Chilisa (2020), researchers often position themselves as the "knower" or teacher, while the researched is seen as the "object" or pupil. "Researchers become the authoritative authors who are not sensitive to the voices of the researched but are more interested in their standing as authorities in the subject they write" (Chilisa, 2020, p. 238). She argues that the researcher should instead consistently self-reflect on 
their relationships with others and examine the quality of those connections. As teacher researchers, we understood the dangers of assuming a deficit gap in the educational experiences of families before they came to the US. We were also aware that schools often fixate on the resettlement, viewing it as a disruption to the children's education that puts them behind, rather than focus on how learning could be bridged equitably (Georgis et al., 2014; Kao et al., 2013; McBrien, 2005; Turney \& Kao, 2009). We learned that Sabiya and Ahmed were resourceful; they drew upon their wisdom and perseverance in helping their daughters overcome their educational issues. We acknowledged Sabiya and Ahmed's feelings of being dismissed by the teachers as well as their commitment to their children's education. Through our questions, listening, and genuine effort to understand, we demonstrated our respect for the family.

During the follow-up interview, Sabiya was excited to share how she collaborated with her middle school son's teacher to support his literacy learning in school. We remembered from the first interview that Mahdi was distracted in school and was not able to advance his reading and writing skills. This time, because of Sabiya's persistence in working with her son's teacher, Mahdi was doing better in school. We noticed a huge difference between how she felt about her children's teachers from the beginning and what was happening now because of Mahdi's progress and his teacher's willingness to accept input from her. Sabiya explained that the teacher invited Mahdi to take on more responsibility and serve as a mentor for a kindergartener because of her belief in him. According to Sabiya, this belief in her son seemed to transfer to his own attitude, causing him to do better in school. Knowing that Sabiya and Ahmed were originally disappointed in the lack of confidence they perceived in their children's teachers toward their children, we asked Sabiya what had prompted the teacher to give her son that responsibility. What changed? Sabiya launched into a story that reflected her trust in the teacher:

Mahdi had some difficulties in reading and writing at the beginning, so I asked for a meeting, and they told me that it is going to be better for him if he joins a private school that teaches the basics. He refused to go because he wanted to stay with his friends. That affected him a lot, so I asked for another interview meeting and asked them to do something for him. They assigned a teacher who can teach him [for] an hour every day. I worked with the teacher to give more responsibilities to Mahdi. Since then, I am calling them, and they tell me that he is doing great in his math level, and for the reading and writing, he is doing well. They are giving him responsibilities, and he is doing well in the teamwork with his friends.

The frustration that Sabiya had expressed to us during the first interview had now changed to feelings of hope and excitement. Her son's teacher was open to her ideas and willing to integrate them into a plan for supporting her son. In turn, she interpreted the school's responsibility to her son and the teacher's responsiveness as a sign of respect for her parenting. Sabiya was pleased that the school was recognizing her knowledge about educational curricula and teaching. Sabiya spoke proudly about her ability to advocate for her son and seemed satisfied with the interactions with her son's teacher. The turnaround between the first and second interviews was remarkable. If we had only conducted the first interview, we would have had a narrow snapshot of the relationship Sabiya and Ahmed had with Mahdi's teacher. In addition, we would not have become aware of how Sabiya was able to find a way to give more input to her son's teacher.

\section{"Your Eyes Open and so Do Your Ears": Broadening Our Understanding as Researchers}

In examining the questions of what we could learn from using decolonizing methods as guideposts for disrupting the research methods we used in the study and how partnering with 
transnational student researchers inform ways of representing the narratives of families, we break down this discussion into three points: (a) the follow-up interview was a crucial element in an embedded case study involving different stakeholders, (b) the modified interview protocol compelled us to examine the potential for deficit language in an interview protocol, and (c) a practice of critical reflexivity in partnership with student researchers helped us to understand the different perspectives that emerged from the family narrative field texts.

First, the embedded case study was useful for helping us understand the network of relationships that refugee families and their children engaged in, which included the home-school liaison who interpreted for them, the children's EL teachers, and their general education. Engaging in conversation with others who worked with the families helped us to better understand Hemon's earlier quotation about individual lives that are made up of details that can only be understood in their totality after being pieced together through narration (2018). We could not have experienced the complexity of an embedded case study (e.g., schools and parents) if we had not centered the second interview on families, asking them what they had learned and what was of value to them. Using an embedded case study also provided us with the opportunity to understand how parents' perspectives shifted after the first interview. By returning to the families for a second interview, we were also able to share with the parents what we had learned about their children's schooling after our interviews with the teachers, home-school liaisons, and administrators. Our conversations with families focused on agency as we sensitively called their attention to their children's schoolwork, such as the example of Suchandra's reading.

Second, a follow-up interview made us more aware of the linguistic component of our interview protocol; language that appears neutral may sound formal and distant as opposed to language that recognizes the historical and material conditions of its audience. There are many studies that have examined the use of language and power in research methods and have valorized the agency in language practices of transnational communities (Campano et al., 2016; Janks, 2010; Lincoln et al., 2008; McKinney, 2017; Motha, 2014). These works framed our understanding of linguistic ideologies inherent in postcolonial settings. In reflecting on our methods, we ponder the importance of partnering with transnational student researchers or community members who can provide more valuable insight about the language that we use in our protocols.

When we returned for the second interview with the families, we brought copies of the prompts from the IRB-approved follow-up interview script. We realized early on that asking the "gaining access" question conveyed a sense of Western presumptuousness. The question also posed a timing challenge; we had to decide when to ask it so that it did not have a trivializing effect, which was reflected in one instance where Cynthia experienced awkwardness when formulating the question to Sabiya just after she had offered Turkish coffee to the research team. Sabiya, along with the rest of the families, did not register the question as relevant or important. This led us to remove the question from the script altogether. Instead, we came to understand that families responded to our comportment with their comfort level and willingness to share stories. This was reflected in our experience making sambusas with Gogo, for example. Asking about how our comportment could be improved led to no new understandings except that the question was inappropriate; instead, we learned that our relationships, relaxed agenda and tone, and demonstrated interest and commitment to our participants and their stories helped our participants trust us and share more of their stories with us. This, too, was reflected in the way Cynthia and Shana considered their identity and roles as parents as well as their awareness of and empathy for the responsibility Gogo had as a parent taking care of five children.

Resisting culturally insensitive approaches may seem obvious; however, in practice, interviewing, question-asking, and member checking may be more complicated when engaging in a relationship informed by transnational and transcultural contexts through intermediaries. These procedural details 
exemplify the microethics that arise in research situations that researchers are not often prepared for through their training (Guillemin \& Gillam, 2004). Simply inserting a feature in our research method to enhance the rapport with our families was not enough; we also needed to interrogate the seemingly neutral and static language that we used in our protocols and the rationale for that language. This we were able to do, especially when we reflected on it with the student researchers. Scholars who conduct qualitative research critique the discourse that is reflected in IRB protocols, especially in studies where English learners are the participants (Perry, 2011; Schrag, 2010). In addition, member checking involves a democratic process that invites participant input, but that process also needs to be unpacked by researchers and families. As we gave up control of managing the interviews, we were able to assess our comportment and behavior through the level of interest that participants had in the discussion. This control symbolized the urge to organize, reduce, and formalize methods that we often do instinctively in conventional research.

Third, in examining our roles as researchers, teachers, and student researchers, we realized that these identities were dynamic and always in flux as we negotiated the knowledge that we coconstructed from the interviews with families and debriefed experiences among the research team members. Through our reflection discussions from the research meetings and the sharing of the identity narratives, we experienced divergent viewpoints, challenging and enriching the ways we interpreted the data. This raises the question of who gets to represent and how. According to Patel (2016), it is difficult for researchers to ignore discussing "the ways in which specific manifestations yield specific locations for the knowledge being offered" (p. 58). For example, during the interview with Sabiya and Ahmed, Sabiya was terribly disappointed that her daughters' teachers could not witness her girls' cleverness because they were too focused on what Sabiya perceived as her daughters' lack of English language skills. Ashraf's respect for the family and his initial description of the intelligence of the family, noting Sabiya's artistic talents as a children's author and painter and the parents' high expectations for their children's education, was also the centerpiece of our discussions. We knew that Ashraf also assisted them with their English classes and was actively involved in supporting the family. They were also good friends, which became even clearer when Ashraf invited us all to his house for dinner. The deep knowledge that the student researchers had of the families, which arose through their shared experiences in refugee camps or in English as a second language classes, manifested into stories that we integrated into our reflections.

Similarly, we learned that Madina and Gogo were related and knew each other well. Madina often visited Gogo's home and helped her with the children or with shopping. In the first interview, we learned that Madina shared Gogo's joking and fun-loving manner-dispositions we witnessed when we noticed how Gogo and her children teased each other during the second interview or when Cynthia and Shana attended Madina's wedding and initially stood on the sidelines of an elaborate community dance while Gogo was one of the leading revelers. Partnering with the student researchers predisposed us to a level of agency that families had, which we were able to understand through trust. Sometimes this understanding starkly contrasted with what we heard in interviews from some of the teachers who had little information about the families.

Decolonizing methods compelled us to resist the deficit notions that we sometimes heard about the students' or families' English linguistic abilities or about the students' lack of formal school preparation. Without an intentional way to meet with families, this was the only information some teachers had of them. English being a barrier is a common narrative that schools perpetuate about English learners. It is certainly a phrase we often heard attributed to the children and their families; it signified a particular power dynamic. Such themes often came from a place of good intentions and an imperative to help the students. At the same time, these one-sided descriptions served to protect what is deemed to be prized or appropriate behavior in the school. According to some language scholars (Flores \& Rosa, 2015; García \& Kleifgen, 2015; Motha, 2014), the continuing dependence on the 
construction of English learners and the teaching of English learners often create divisions between native and non-native speakers, sometimes perpetuating the notion of difference even more. Difference plays a pivotal role in the formation of school as a site of coloniality, where the system is created to "segment land, people, and relationships among them into strata" (Patel, 2016). As "insiders" in the field of education, both troubled by displays of inequity and inspired by movements of school personnel and students within it who endeavor to make it better, we are still aware of a hidden curriculum that often leans toward the normative idea of "fixing" students who are considered different. We also know of many teachers who resist overarching generalizations about their students and strive to help students academically and socially. Sometimes, we struggled with reconciling these divergent viewpoints and considered how to co-construct knowledge if participant groups reflected different epistemic ideas about the other, especially if it related to language and learning. We simply held on to these incommensurable tensions about culture and language informed by power dynamics, recognizing that these contact zones of conflict could also become spaces for understanding praxis (Pratt, 1999). How these differences are managed depends on the researchers' willingness to tolerate ambiguity. The relational aspects of doing research will always be complicated and messy, but they are necessary for troubling the colonial notion of knowledge production as a universal concept.

\section{Conclusion}

In continuing the work of critically examining partnerships between schools and families with refugee experiences, we recognize that, through certain advantages, researchers and school personnel are ideally positioned to interrogate their own approaches with families. Considering our commitments to mediate information between schools and families, we see a potential for reciprocal reflection between families and teachers. Using our research findings to help them reflect back information about each other could potentially create opportunities for families and teachers to get to know each other and overcome the systemic and power constraints in order to build relationships. We were able to return to the teachers and share broader narratives about their students, hoping to expand their limited awareness of the families, and the research team was intentional about demystifying the school system for families. Most of the families we talked to were also grateful that their children had the opportunity to attend schools in the US. In general, they perceived the school community to be safer and more organized than the refugee camp schools, and in many cases, parents were impressed with some teachers who showed a deep interest in their children. Not all of the teachers had the same perspectives that we described in this paper, and not all families shared similar ideas about their children's schooling. Postcolonial theory offers an entry way into deconstructing research relationships with refugee families and highlighting the idea of alterity in an embedded case study that features different and dynamic transnational and transcultural perspectives. This study sought to describe the complexity of Centering Connections and examine the trust families had in us as well as the research team's commitment to encourage schools to support equitable partnerships with the families in the future. A shift towards family-centered outcomes requires a concerted effort to critique Western ways of knowing in conventional qualitative research studies.

\section{References}

Andreotti, V. (2011). Actionable postcolonial theory in education. Palgrave MacMillan Publishing.

Bermúdez, J.M., Muruthi, B.A., \& Jordan, L.S. (2016). Decolonizing research methods for family science: Creating space at the center. Journal of Family Theory \& Review, 8, 192-206.

https://doi.10.111/jftr.12139

Bhabha, H. K. (1994). The location of culture. Routledge.

Block, K., Warr, D., Gibbs, L., \& Riggs, E. (2013). Addressing ethical and methodological 
challenges in research with refugee-background young people: Reflections from the field. Journal of Refugee Studies, 26(1), 69-87. https://doi.org/10.1093/jrs/ fes002

Campano, G., Ghiso, M. P., \& Welch, B. J. (2016). Partnering with immigrant communities. Teachers College Press.

Carter, S. M., Jordens, C. F. C., McGrath, C., \& Little, M. (2008). You have to make something of all that rubbish, do you? An empirical investigation of the social process of qualitative research. Qualitative Health Research, 18(9), 1264-1276. https://doi.org/10.1177/1049732308321753

Chilisa, B. (2020). Indigenous research methodologies (2nd ed.). Sage.

Clandinin, D. J., \& Connelly, F. M. (2000). Narrative inquiry: Experience and story in qualitative research. Jossey-Bass.

DeHaene, L., Grietens, H., \& Verschueren, K. (2010). Holding harm: Narrative methods in mental health research on refugee trauma. Qualitative Health Research, 20(12), 1664-1676. https://doi.org/10.1177/1049732310376521

Dryden-Peterson, S. (2015). The educational experiences of refugee children in countries of first asylum. Migration Policy Institute.

Dyregrov, K., Dyregrov, A., \& Raundalen, M. (2000). Refugee families' experience of research participation. Journal of Traumatic Stress, 13(3), 413-426. https://doi.org/10.1023/A:1007777006605

Ellis, B. H., Kia-Keating, M., Yusuf, S. A., Lincoln, A., \& Nur, A. (2007). Ethical research in refugee communities and the use of community participatory methods. Transcultural Psychiatry, 44(3), 459-481. https://doi.org/10.1177/1363461507081642

Fanon, F. (1963). The wretched of the earth. Grove Press.

Flores, N., \& Rosa, J. (2015). Undoing appropriateness: Raciolinguistic ideologies and language diversity in education. Harvard Educational Review, 85(2), 149-172. https://doi.org/10.17763/0017-8055.85.2.149

Gandhi, L. (2019). Postcolonial theory. Columbia University Press.

García, O. G., \& Kleifgen, J. A. (2018). Educating emergent bilinguals. Teachers College Press.

Georgis, R., Gokiert, R. J., Ford, D. M., \& Ali, M. (2014). Creating inclusive parent engagement practices: Lessons learned from a school community collaborative supporting newcomer refugee families. Multicultural Education, 21(3-4), 23-27. https://www.proquest.com/openview/e5eb7d9a15b297a6465552c1720a340d/1?pqorigsite $=$ gscholar\&cbl $=33246$

Guillemin, M., \& Gillam, L. (2004). Ethics, reflexivity, and "ethically important moments" in research. Qualitative Inquiry, 10(2), 261-280. https://doi.org/10.1177/1077800403262360

Gutiérrez, K. D., \& Rogoff, B. (2003). Cultural Ways of Learning: Individual Traits or Repertoires of Practice. Educational Researcher, 32, 19-25. https://doi.org/10.3102/0013189X032005019

Haddad, E. (2004). Who is (not) a refugee? EUI Working Paper SPS No. 2004/6. Florence: European University Institute.

Haines, S. J., Francis, G. L., Kyzar, K., Aldersey, H., \& Adams, N. B. (2018). Family-professional partnerships with refugee families of children with disabilities. International Review of Research on Developmental Disabilities, 54, 35-70. https://doi.org/10.1016/bs.irrdd.2018.07.002

Haines, S. J., Summers, J. A., Turnbull, A. P., \& Turnbull, H. R. (2015). Family partnership with a Head Start agency: A case study of a refugee family. National Head Start Research Association's Dialog, 17(4), 22-49. https://journals.uncc.edu/dialog/article/view/168/354

Hemon, A. (2018). God's fate. In V. T. Nguyen (Ed.), The displaced (pp. 91-104). Abrams Press. 
Ishimaru, A. M., Bang, M., Valladares, M. R., Nolan, C. M., Tavares, H., Rajendran, A., \& Chang, K. (2019). Recasting families and communities as co-designers of education in tumultuous times. National Education Policy Center. http://nepc.colorado.edu/publication/family-leadership.

Isik-Ercan, Z. (2010). In pursuit of a new perspective in the education of children of the refugees: Advocacy for the "family". Educational Sciences: Theory and Practice, 12(4), 3025-3038

Jacobsen, K., \& Landau, L. (2003). The dual imperative in refugee research: Some methodological and ethical considerations in social science research on forced migrants.

Disasters, 27(3), 185-206. https://doi.org/10.1111/1467-7717.00228

Janks, H. (2010). Literacy and power. Routledge.

Kao, G., Vaquera, E., \& Goyette, K. (2013). Education and Immigration. Polity Press.

Lincoln, Y. S., \& González y González, E. M. (2008). The search for emerging decolonizing Methodologies in qualitative research: Further strategies for liberatory and democratic inquiry. Qualitative Inquiry, 14(5), 784-803. https://doi.org/10.1177/1077800408318304

Mackenzie, C., McDowell, C., \& Pittaway, E. (2007). Beyond 'do no harm': The challenge of constructing ethical relationships in refugee research. Journal of Refugee Studies, 20(2), 299-319. https://doi.org/10.1093/jrs/fem008

Maxwell, J. A. (2012). Qualitative research design: An interactive approach (3rd ed.). Sage.

Mignolo, W. D., \& Walsh, C. E. (2018). On decoloniality. Duke University Press.

Motha, S. (2014). Race, empire, and English language teaching. Teachers College Press.

McBrien, J. L. (2005). Educational needs and barriers for refugee students in the United States: A review of the literature. Review of Educational Research, 75(3), 329-364.

https://doi.org/10.3102/00346543075003329

McKinney, C. (2017). Language and power in post-colonial schooling. Routledge.

Nakkash, R., Makhoul, J., \& Afifi, R. (2009). Obtaining informed consent: Observations from community research with refugee and impoverished youth. Journal of Medical Ethics, 35(10), 638-643. https://doi.org/10.1136/jme.2008.028936

Nguyen, V.T. (Ed.) (2018). The displaced: Refugee writers on refugee lives. Abrams Press.

Olivos, E. M., Gallagher, R. J., \& Aguilar, J. (2010). Fostering collaboration with culturally and linguistically diverse families of children with moderate to severe disabilities. Journal of Educational and Psychological Consulting, 20, 28-40. https//doi.org/10.1080/10474410903535372

Patel, L. (2016). Decolonizing educational research: From ownership to answerability. Routledge.

Perry, K. (2011). Ethics, vulnerability, and speakers of other languages: How university IRBs (do not) speak to research involving refugee participants. Qualitative Inquiry, 17(10), 899-912. https://doi.org/10.1177/1077800411425006

Pittaway, E., Bartolome, I. L., \& Hugman, R. (2010). 'Stop stealing our stories': The ethics of research with vulnerable populations. Journal of Human Rights Practice, 2(2), 229-251. https://doi.org/10.1093/jhuman/huq004

Pratt, M.L. (1999). Arts of the contact zone. In J.M. Wolff (Ed.) Professing in the contact zone (pp. 1-18). National Council of Teachers of English.

Reyes, C. C., Haines, S. J., \& Clark-Keefe, K. (2021). Humanizing methodologies in educational research: Centering non-dominant communities. Teachers College Press.

Said, E. (1993). Culture and imperialism. Vintage Books.

Schrag, Z. (2010). Ethical imperialism: Institutional Review Boards and the social sciences, 1965-2009. The John Hopkins University Press.

Smith, L.T. (2012). Decolonizing methodologies. Zed Books.

Smith, L. T., Tuck, E., \& Yang, K. W. (2019). Indigenous and decolonizing studies in education. Routledg Spivak, G. C. (1988). Can the subaltern speak? In C. Nelson \& L. Grossberg (Eds.), Marxism and the interpretation of culture (pp. 271-313). University of Illinois Press. 
Turney, K., \& Kao, G. (2009). Barriers to school involvement: Are immigrant parents disadvantaged? Journal of Educational Research, 102(4), 257-271. https://doi.org/10.3200/JOER.102.4.257-271

Windchief, S., \& San Pedro, T. (2019). Applying indigenous research methods: Storying with peoples and communities. Routledge.

Yin, R. K. (2009). Case study research: Design and methods (4th ed.). Sage. 